\title{
Association of Oral Submucous Fibrosis in Patients with and without Habit - A Retrospective Study
}

Research Article

Jaya keerthana $S^{1}$, Maragathavalli. $\mathrm{G}^{2 *}$

${ }^{1}$ Graduate Student, Saveetha Dental College and Hospitals, Saveetha Institute of Medical and Technical Sciences, Saveetha University, Chennai, India. ${ }^{2}$ Professor, Department of Oral Medicine and Radiology, Saveetha Dental College and Hospitals, Saveetha Institute of Medical and Technical Sciences, Saveetha University, Chennai, 600077, India.

\section{Abstract}

\begin{abstract}
In Indian subcontinent Tobacco, betel nut and areca are used in various forms. The habit is not restricted and this habit is gaining popularity among people. The association between these habit and OSMF is well proved, however the influence of age and gender related to the habit on the prognosis and behaviour needs further study.Aim of the study is to evaluate the association of OSMF in patients with and without habit.A total of 94 OSMF patients were taken into the study from various clinical departments, Saveetha dental College, Chennai.The datas were collected from 86000 patient reports who reported for various dental treatments in a period of 9 months from june 2019 to march 2020. This study is a retrospective study where the datas were collected only from the patient reports. The datas were then analysed in version 19 SPSS software. Out of 94 cases, majority was males 85 , and female 7 in number. OSMF was more in the age groups of 20 to 40 years and 41 to 60 years. There was only $2.1 \%$ OSMF patients without habit among outpatients. Results showed that the study is statistically insignificant.
\end{abstract}

Keywords: Age; Fibrosis; habit; OSMF; Patients.

\section{Introduction}

Oral submucous fibrosis is a chronic progressive disease that predominantly affects the South East Asian people [1]. OSMF is found to be a multifactorial aetiology including genetic susceptibility, autoimmunity, iron, excessive Chilli consumption and vitamin D deficiency [2]. Strongly associated with areca nut chewing and Paan [3].

Oral fibrosis is caused due to increased synthesis of collagen and in turn induces the production of free radicals and reactive oxygen species. This leads to high rate of oxidation or peroxidation of polyunsaturated fatty acids which affect essentials of all membrane which may Induce tumorogenesis [4].

OSMF is classified as an oral potential malignant disorder (OPMD) [5]. Patient with OSMF have reported with higher risk of developing oral squamous cell carcinoma (0SCC), compared to other OPMDS $[6,7]$ Oral carcinoma develops from oral poten- tially malignant disorders (OPMDs) [8]. Salivary markers for the detection of malignant transformation of oral potentially malignant disorders (OPMD) are noninvasive diagnostic markers and should be analyzed for efficiency as surrogate markers [9].

Metastatic malignancies of the oral cavity are rare lesions, accounting for only $1-4 \%$ of all oral malignancies and can occur in the jaw bones, the oral soft tissues or even both [10]. Oral mucositis has severe physical and mental disability during the course of the treatment prompting interventions either to prevent such occurrence or treat them [11].

Although 7.6\% of OSMF cases transform to oral squamous cell carcinoma in a 17 year follow-up study reported in 1970 [12], other studies with smaller follow-up period Report malignant transformation rates ranging from 1.9 to $9 \%$ [13-15] depending on diagnostic criteria and duration of follow-up [16]. Previously our team had conducted numerous clinical trials [17-23] and lab animal studies [24-28] and in vitro studies over the past 5 years [29-31].

\footnotetext{
*Corresponding Author:

Maragathavalli $G$

Professor, Department of Oral Medicine \& Radiology, Saveetha Dental College and Hospitals, Saveetha Institute of Medical and Technical Sciences, Saveetha University, Chennai, 600077, India

Tel: 9445171146

E-mail: maragathavalli@saveetha.com

Received: October 07,2020

Accepted: November 22, 2020

Published: November 25, 2020

Citation: Jaya Keerthana S, Maragathavalli. G. Association of Oral Submucous Fibrosis in Patients with and without Habit - A Retrospective Study. Int J Dentistry Oral Sci. 2020;7(11):1045-1048. doi: http://dx.doi.org/10.19070/2377-8075-20000206

Copyright: Maragathavalli $\mathbf{G}^{\circ} 2020$. This is an open-access article distributed under the terms of the Creative Commons Attribution License, which permits unrestricted use,
} distribution and reproduction in any medium, provided the original author and source are credited. 
The aim of this study is to evaluate the association of OSMF in patients with and without habit.

\section{Materials and Methods}

A total 94 patients were taken into the study, these patients were selected from the outpatient of each clinical departments who had come for various dental treatments, saveetha dental College and Hospital Chennai, India.

The inclusion criteria of the study was - OSMF patients who had come for dental treatments (June 2019 to April 2020). Two examiners were involved in the study, both evaluated the data from 86000 patient reports. The criteria for consideration were-OSMF patient.

The ethical committee approval was obtained from the institutional ethical committee. Simple random sampling was done in order to eliminate bias. The SPSS software version 19 was used to analyse the collected data.

\section{Results and Discussion}

Sri Vastaava $\mathrm{R}$, did a similar study on prevalence of OSMF in patients visiting dental College in Kanpur and he found that patient with areca nut habit and increased occurrence of OSMF [32].

Comparing the above studies, this study has almost $97.9 \%$ of patients had habits and only $2.1 \%$ had no habits.

This study reports a retrospective investigation done only with the information obtained from the 86000 patients reports. In future large population and long-term follow-up can be considered for further studies and helpful for awareness of habit and used to estimate and prevent from OSMF and maintain good oral health.

\section{Conclusion}

Within the limitations of the study, it is shown that the majority of male patients between the age group with habits were affected with OSMF. This study also implies that there is no statistically significant difference between age, gender and habit. Clinicians should emphasize on cessation of habit and give awareness on OSMF and complications.

\section{Acknowledgement}

The study was supported by the University who provided insights and expertise that greatly assisted the study. We would also like to thank the reviewers of the article for their insights.

Figure 1. Bar chart represent the frequency of OSMF in patients with and without habit, habit was present for $97.87 \%$ of the patients and it was absent in $2.1 \%$ of the patients.

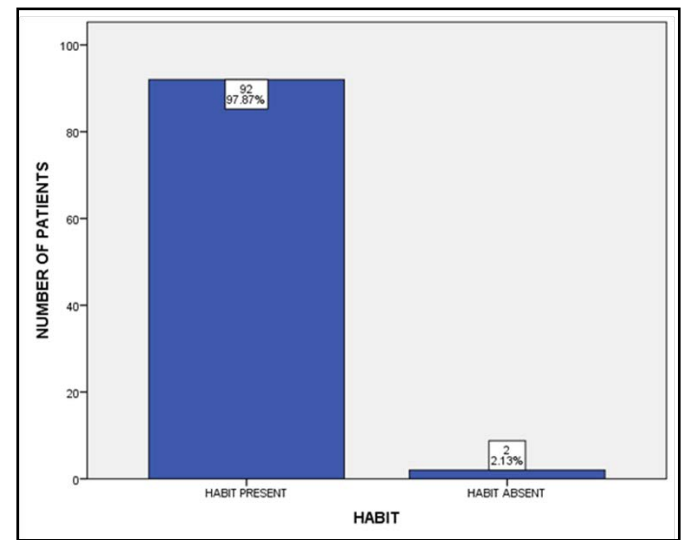

Figure 2. Bar chart represents the association between different age groups and gender of patients with OSMF. $\mathrm{X}$ axis represents different age groups and $Y$ axis represents the number of patients. Majority of Males (green) in the age group between 20-40 years are affected with OSMF. Chi square association test was done [Chi square value-5.175 and $p$ value - 0.075 $(p>0.05)]$ showing there is no statistically significant difference between the age group and gender affected with OSMF.

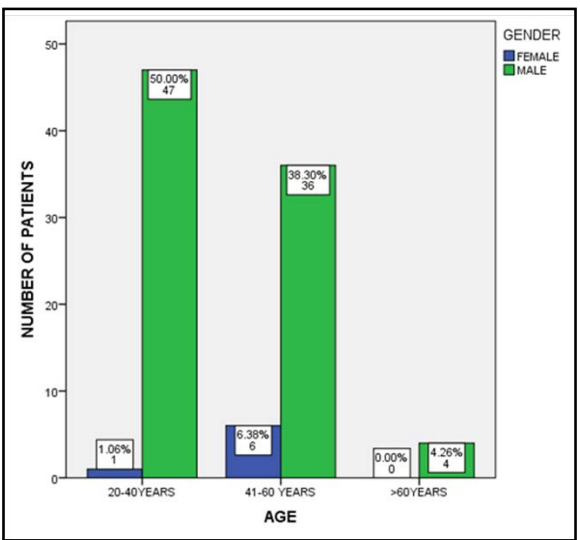


Figure 3. Bar chart represents the association of age and habit in patients with OSMF. X axis represents different age groups and $\mathrm{Y}$ axis represents number of patients with (blue) and without habit (green). Majority of patients with a habit (blue) between the age group of 20-40 years were affected with OSMF. Chi square test was done [chi square value - 0.100 and $p$ value $-0.951(p>0.05)$ ]implying that there is no statistically significant difference between the age group and patients with and without habit.

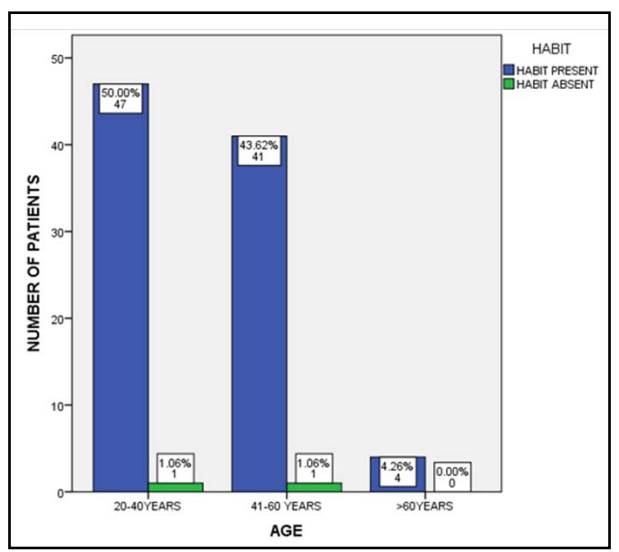

Figure 4. Bar chart represents the association of gender and habit. Xaxis represents the gender and $\mathrm{Y}$ axis represents the number of patients with (blue) and without habit (green). Majority of male patients with the habit were affected with OSMF. Chi square test was done [Chi square value 0.164 and $p$ value- $0.685(\mathrm{p}>0.05)$ ] implying that there is no statically significant difference between the gender and the habits.

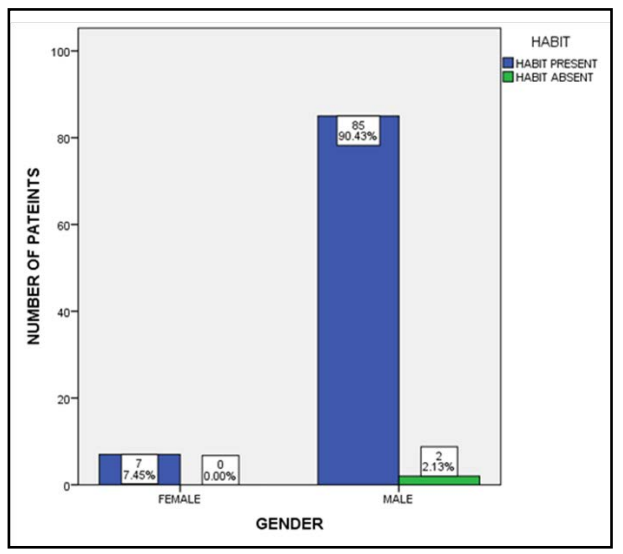

\section{References}

[1]. Rajendran R. Oral submucous fibrosis. J Oral Maxillofac Pathol. 2003 Jan $1 ; 7(1): 1$.

[2]. Koshti SS, Barpande S. Quantification of plasma fibrinogen degradation products in oral submucous fibrosis: A clinicopathologic study. J. Oral Maxillofac. Pathol.. 2007 Jul 1;11(2):48.

[3]. Shah N, Sharma PP. Role of chewing and smoking habits in the etiology of oral submucous fibrosis (OSF): a case-control study. J Oral Pathol Med. 1998 Nov;27(10):475-9.Pubmed PMID: 9831959.

[4]. R S, Pai A, Yaji A. Habit History in Oral Submucous Fibrosis: Have We Over Emphasized? Asian Pac J Cancer Prev. 2019 Feb 26;20(2):451-455. Pubmed PMID: 30803207.

[5]. More CB, Das S, Patel H, Adalja C, Kamatchi V, Venkatesh R. Proposed clinical classification for oral submucous fibrosis. Oral Oncol. 2012 Mar $1 ; 48(3): 200-2$.

[6]. Heck JE, Marcotte EL, Argos M, Parvez F, Ahmed A, Islam T, et al. Betel quid chewing in rural Bangladesh: prevalence, predictors and relationship to blood pressure. Int J Epidemiol. 2012 Apr;41(2):462-71.Pubmed PMID: 22253307.

[7]. Aziz SR. Oral submucous fibrosis: case report and review of diagnosis and treatment. J Oral Maxillofac Surg. 2008 Nov;66(11):2386-9.Pubmed PMID: 18940512

[8]. Venugopal A, Uma Maheswari TN. Expression of matrix metalloproteinase-9 in oral potentially malignant disorders: A systematic review. J Oral Maxillofac Pathol. 2016 Sep-Dec;20(3):474-479.Pubmed PMID: 27721614.

[9]. Maheswari TNU, Venugopal A, Sureshbabu NM, Ramani P. Salivary micro RNA as a potential biomarker in oral potentially malignant disorders: A systematic review. Ci Ji Yi Xue Za Zhi. 2018 Apr-Jun;30(2):55-60.Pubmed PMID: 29875583
[10]. Misra SR, Shankar YU, Rastogi V, Maragathavalli G. Metastatic hepatocellular carcinoma in the maxilla and mandible, an extremely rare presentation. Contemp Clin Dent. 2015 Mar;6(Suppl 1):S117-21.Pubmed PMID: 25821363.

[11]. Chaitanya NC, Muthukrishnan A, Babu DBG, Kumari CS, Lakshmi MA Palat G, et al. Role of Vitamin E and Vitamin A in Oral Mucositis Induced by Cancer Chemo/Radiotherapy- A Meta-analysis. J Clin Diagn Res. 2017 May;11(5):ZE06-ZE09.Pubmed PMID: 28658926.

[12]. Murti PR, Bhonsle RB, Pindborg JJ, Daftary DK, Gupta PC, Mehta FS. Malignant transformation rate in oral submucous fibrosis over a 17 -year period. Community Dent Oral Epidemiol. 1985 Dec;13(6):340-1.Pubmed PMID: 3866655.

[13]. PAYMASTER JC. Cancer of the buccal mucosa; a clinical study of 650 cases in Indian patients. Cancer. 1956 May-Jun;9(3):431-5.Pubmed PMID: 13329991.

[14]. Hsue SS, Wang WC, Chen CH, Lin CC, Chen YK, Lin LM. Malignant transformation in 1458 patients with potentially malignant oral mucosal disorders: a follow-up study based in a Taiwanese hospital. J Oral Pathol Med. 2007 Jan;36(1):25-9.Pubmed PMID: 17181738.

[15]. Arakeri G, Patil SG, Aljabab AS, Lin KC, Merkx MAW, Gao S, et al. Oral submucous fibrosis: An update on pathophysiology of malignant transformation. J Oral Pathol Med. 2017 Jul;46(6):413-417.Pubmed PMID: 28391621.

[16]. Ray JG, Ranganathan K, Chattopadhyay A. Malignant transformation of oral submucous fibrosis: overview of histopathological aspects. Oral Surg Oral Med Oral Pathol Oral Radiol. 2016 Aug;122(2):200-9.Pubmed PMID: 27422418

[17]. PradeepKumar AR, Shemesh H, Jothilatha S, Vijayabharathi R, Jayalakshmi S, Kishen A. Diagnosis of Vertical Root Fractures in Restored Endodontically Treated Teeth: A Time-dependent Retrospective Cohort Study. J Endod. 2016 Aug;42(8):1175-80.Pubmed PMID: 27339633. 
[18]. Ramamoorthi S, Nivedhitha MS, Divyanand MJ. Comparative evaluation of postoperative pain after using endodontic needle and EndoActivator during root canal irrigation: A randomised controlled trial. Aust Endod J. 2015 Aug;41(2):78-87.Pubmed PMID: 25195661.

[19]. Kadam NS, Kunte SS, Patel AR, Shah PP, Lodaya RR, Lakade LS. Comparative evaluation of the effect of pomegranate peel extract and chlorhexidine $0.2 \%$ mouthwash on salivary $\mathrm{pH}$ in children between 6 and 8 years of age: An in vivo study. J Int Oral Health. 2019 Jan 1;11(1):40.

[20]. Ramanathan S, Solete P. Cone-beam Computed Tomography Evaluation of Root Canal Preparation using Various Rotary Instruments: An in vitro Study. The J Contemp Dent Pract. 2015 Nov 1;16(11):869-72.

[21]. Haripriya S, Ajitha P. Antimicrobial efficacy of silver nanoparticles of Aloe vera. J. Adv. Pharm. Educ. Res. Apr-Jun. 2017;7(2).

[22]. Kumar JS, Jayalakshmi S. Bond Failure and Its Prevention in Composite Restoration-A Review. J. Pharm. Sci. Res. 2016 Jul 1;8(7):627.

[23]. Rani L. Sterilization protocols in dentistry-A review. J. Pharm. Sci. Res. 2016 Jun 1;8(6):558.

[24]. Siddique R, Sureshbabu NM, Somasundaram J, Jacob B, Selvam D. Qualitative and quantitative analysis of precipitate formation following interaction of chlorhexidine with sodium hypochlorite, neem, and tulsi. J Conserv Dent. 2019 Jan-Feb;22(1):40-47.Pubmed PMID: 30820081.

[25]. Mohanty S, Ramesh S. Fracture resistance of three posterior restorative materials: A preliminary in vitro study. J. Adv. Pharm. Educ. Res. 2017 JulSep;7(3).
[26]. Mohanty S, Ramesh S, Priya VV, Gayathri R. Inhibition of purE Gene Using Herbal Compounds to Treat Oral Diseases Caused by Oral PathogensAn in silico Study. J. Pharm. Sci. Res. 2017 Jul 1;9(7):1246.

[27]. Kumaravadivel MS, Pradeep S. Recent advancements of endodontic sealers-a review. Int. J. Pharm. Technol. 2016;8:4060-75.

[28]. Srinivasan S, Pradeep S. The attitude of dentists towards the prescription of antibiotics during endodontic treatment-a questionnaire based study. Int J Pharm Technol. 2016;8:15895-900.

[29]. Kumar SA, Ajitha P. Evaluation of compressive strength between Cention N and high copper amalgam-An in vitro study. Drug Invention Today. 2019 Feb 15;12(2).

[30]. Rajakeerthi R, Ms N. Natural Product as the Storage medium for an avulsed tooth-A Systematic Review. Cumhur. Dent. J. 2019;22(2):249-56.

[31]. Rajendran R, Kunjusankaran RN, Sandhya R, Anilkumar A, Santhosh R, Patil SR. Comparative Evaluation of Remineralizing Potential of a Paste Containing Bioactive Glass and a Topical Cream Containing Casein Phosphopeptide-Amorphous Calcium Phosphate: An in Vitro Study. Pesqui. Bras. Odontopediatria Clín. Integr. 2019;19:1-10.

[32]. Srivastava R, Jyoti B, Pradhan D, Siddiqui Z. Prevalence of oral submucous fibrosis in patients visiting dental OPD of a dental college in Kanpur: A demographic study. J Family Med Prim Care. 2019 Aug 28;8(8):2612-2617. Pubmed PMID: 31548942. 